Strategi Pengembangan Daerah Tertinggal Di Kabupaten Garut

( Endah Djuwendah, Hepi Hapsari, Eddy Renaldy dan Zumi Saidah )

\title{
STRATEGI PENGEMBANGAN \\ DAERAH TERTINGGAL DI KABUPATEN GARUT
}

\author{
Endah Djuwendah, Hepi Hapsari, Eddy Renaldy dan Zumi Saidah \\ Jurusan Sosial Ekonomi Fakultas Pertanian Universitas Padjadjaran \\ E-mail : endah_djuwendah@yahoo.com
}

\begin{abstract}
ABSTRAK. Penelitian ini bertujuan untuk mengetahui aktivitas ekonomi yang dapat dikembangkan di wilayah Kabupaten Garut bagian selatan dan strategi dalam pembangunan daerah tertinggal di Garut Selatan.Metode yang digunakan adalah survey deskriptif dengan menggunakan data primer dan data skunder dengan unit analisisnya 16 kecamatan. Teknis analisis menggunakan indek produktivitas relatif (IPR)dan analisis SWOT. Hasil penelitian menunjukkan bahwa Kabupaten Garut bagian selatan memiliki sumberdaya alam yang berciri sektor pertanian,perikanan, peternakan pertambangan dan energi serta pariwisata. Terdapat lima strategi utama untuk pengembangan daerah tertinggal di wilayah Garut Selatan yaitu dengan cara memadukan pembangunan sektoral dan kewilayahan yang berbasis potensi sumberdaya lokal melalui : (a) Peningkatan akses kerjasama berbagai sektor pemerintah, swasta dan perguruan tinggi untuk mengatasi keterbatasan dana pembangunan berkelanjutan (b) pengembangan ekonomi berbasis potensi lokal dengan cara pengembangan komoditas unggulan spesifik lokasi dan produk olahan melalui teknologi tepat guna dan perluasan pemasaran, (c) optimalisasi peran pusat pelayanan dengan cara melengkapi ketersediaan sarana dan prasarana serta keterkaitan sosial ekonomi dengan daerah pelayanannya, (d) peningkatan kualitas SDM dan pemberdayaan masyarakat melalui pendidikan/pelatihan dan pembinaan kelembagaan berbasis pedesaan, (e) optimalisasi peran kabupaten garut sebagai daerah penyangga Jawa barat melalui efektifitas penggelolaan tata ruang kawasan lindung dan budidaya dengan mempertimbangkan kawasan rawan bencana alam.
\end{abstract}

Kata Kunci: Strategi pengembangan wilayah, daerah tertinggal.

\section{STRATEGY DEVELOPMENT OF DISADVANTAGED AREAS IN GARUT REGENCY}

\begin{abstract}
This study aims to determine the economic activity that ca be developed in the southern part of the district of Garut and strategies in the development of disadvantaged areas in Garut Selatan. Metode used is descriptive survey using data from the primary and secondary data analysis unit 16 districts. Technical analysis uses the relative productivity index (IPR) and SWOT analysis. The results showed that the southern part of Garut regency have natural resources, characterized by agriculture, fisheries, livestock and energy mining and tourism. There are five main strategies for the development of disadvantaged areas in South Garut region that is by combining sectoral and territorial development potential based on local resources through: (a) to increase access to collaboration across government, private and university funds to overcome the limitations of the study showed that the sustainable development, (b) based on the potential for local economic development through the development of specific commodities and processed products through appropriate technology and marketing expansion, (c) Optimization of the central role of the service in a way complements the availability of infrastructure and socio-economic linkages with hinterland, (d) improving the quality of human resources and community empowerment through education / training and rural-based institution building, (e) optimizing the role of Garut district as a buffer zone west Java through spatial management effectiveness of protected areas and cultivation considering the natural disaster-prone areas.
\end{abstract}

Keywords: Regional Development strategy, disadvantaged areas

\section{PENDAHULUAN}

Perkembangan suatu wilayah tidak dapat berlangsung secara merata, Hal ini disebabkan oleh banyak faktor, baik faktor alami (geografis, sumberdaya manusia, sumberdaya alam) maupun faktor buatan manusia (termasuk infrastruktur dan sumberdaya sosial) yang tersebar secara tidak merata dalam wilayah. Kondisi ini selain menimbulkan ketimpangan dalam pembangunan juga dapat menjadi salah satu penyebab timbulnya daerah tertinggal atau terbelakang.

Daerah tertinggal adalah kabupaten yang relatif kurang berkembang dibandingkan daerah lain dalam skala nasional 
dan berpenduduk relatif tertinggal dari segi ekonomi, sosial, kesehatan dan pendidikan. Menurut Bappenas, wilayah tertinggal pada umumnya dicirikan dengan letak geografis yang relatif terpencil atau wilayah yang miskin sumberdaya alam atau rawan bencana. Menurut Kementrian Negara Pembangunan Daerah Tertinggal RI (2007) penentuan kriteria daerah tertinggal menggukan pendekatan enam kriteria yaitu:

(1) perekonomian masyarakat, (2) sumberdaya manusia,(3) prasarana dan sarana, (4) kemampuan keuangan daerah, (5) aksesibilitas dan (6) karakteristik daerah.

Berdasarkan pendekatan tersebut Kabupaten Garut merupakan salah satu dari dua kabupaten yang tergolong daerah tertinggal di Jawa Barat. Kabupaten Garut pada tahun 2010 diperkirakan memiliki penduduk miskin 369.731 orang dengan proporsi sebesar $15,32 \%$ dari seluruh penduduk dan angka pengangguran usia kerja diatas 15 tahun mencapai 50.134 orang. Angka indeks pembangunan masyarakat (IPM) Kabupaten Garut tahun 2010 mencapai 71,36 dengan indeks kesehatan 67,67, angka harapan hidup 64,60 tahun dan kemampuan daya beli per tahun sebesar Rp 637.490 (BPS,2011).

Hasil analisis hirarki pusat pertumbuhan, kecuali Kecamatan Cikajang, wilayah Garut Selatan berperan sebagai pusat pelayanan terkecil (orde IV) yang hanya mampu melayani desa-desa di sekitarnya (Djuwendah dkk, 2010). Garut selatan kecuali Kecamatan Cikajang, termasuk dalam kluster III atau merupakan kategori daerah tertinggal (Bappeda, 2010). Selain mendapat predikat daerah tertinggal, ketimpangan dalam lingkup pembangunan daerah Garut juga terjadi antar wilayah pengembangan (WP) Utara, Tengah dan Selatan. Pertumbuhan ekonomi wilayah Garut Selatan masih rendah, terlihat dari kontribusi nilai tambah bruto sektoral kecamatankecamatan di Kabupaten Garut bagian selatan pada tahun 2007 paling rendah, yaitu $24,37 \%$ dibandingkan wilayah Garut Tengah senilai 46,05\%, dan wilayah Garut Utara sebesar 29,58\%. Hal ini menyebabkan perkembangan wilayah Garut Selatan menjadi relatif terbelakang dibandingkan dengan wilayah lainnya.

Faktor-faktor yang diduga penyebab ketertinggalan pertumbuhan wilayah Garut Selatan antara lain tidak adanya leading sector yang dapat mempercepat pertumbuhan ekonomi wilayah, potensi sumberdaya alam belum dimanfaatkan secara maksimal, yang mungkin disebabkan oleh keterbatasan sumberdaya manusia dan modal, rendahnya tingkat pendidikan masyarakat akan berpengaruh terhadap partisipasi publik dalam suatu perencanaan pembangunan, kebijakan pemerintah baik pemerintah pusat maupun daerah dalam pengembangan wilayah Garut Selatan belum dapat sepenuhnya terimplementasikan secara optimal.

Percepatan pembangunannya di Garut selatan juga mengalami kesulitan karena karakteristik wilayahnya merupakan kawasan konservasi (non budidaya) dan rawan bencana. Padahal dari potensi yang ada, wilayah Garut Selatan memiliki sumberdaya alam yang melimpah untuk dikembangkan diantaranya sektor pertanian, perikanan, kelautan, pariwisata dan sektor pertambangan (Lestari, 2010).

Pembangunan di wilayah Garut Selatan memerlukan penanganan yang optimal guna mendukung perkembangan wilayah berbasis sumberdaya lokal agar sejajar dengan daerah lain yang telah berkembang. Oleh karena itu diperlukan suatu kajian mengenai potensi ekonomi wilayah dan strategi pembangunan untuk percepatan pembangunan daerah tertinggal di Kabupaten Garut.

\section{METODE}

Desain penelitian yang digunakan adalah survey deskriptif dengan unit analisis 16 kecamatan di Kabupaten Garut dan obyek penelitiannya adalah strategi pengembangan daerah tertinggal. Data yang digunakan terdiri dari data primer dan sekunder dari arsip, dokumen, dan hasil penelitian dari BPS, Bappeda dan instansi terkait. Teknik pengolahan data dilakukan menggunakan Indeks Produktivitas Relatif (IPR) dan SWOT. 


\section{HASIL DAN PEMBAHASAN}

\section{Kondisi Umum Perekonomian Daerah Kabupaten Garut}

Kabupaten Garut merupakan daerah yang memiliki sumberdaya alam yang besar berciri sektor pertanian dan industri berbasis pertanian (agroindustri). Laju Pertumbuhan Ekonomi(LPE) Kabupaten Garut pada tahun 2010 adalah 5,31 persen dan PDRB per kapitanya atas dasar harga berlaku Rp10.284.612. Struktur ekonomi Kabupaten Garut, didominasi sektor pertanian, dengan kontribusi pembentukan nilai tambah sebesar 47,1\% terhadap PDRB (Produk Domestik Regional Bruto); diikuti sektor perdagangan, jasa dan pariwisata sebesar $26,4 \%$, jasa lain $10 \%$, industri $9 \%$, dan sektor lain kurang dari $2 \%$ (BPS, 2011)

IPR suatu sektor merupakan ukuran untuk melihat tingkat produktifitas tenaga kerja pada sektor ekonomi di suatu wilayah de-ngan cara membandingkan share sektor terhadap PDRB dengan share dalam penyerapan tenaga kerja sekaligus memotret proses transpormasi struktur ekonomi dari pertanian ke industri.

Tabel 1. Perkembangan Indeks Produktifitas Relatif Kabupaten Garut

\begin{tabular}{clccc}
\hline \multirow{2}{*}{ No } & Lapangan & \multicolumn{4}{c}{ Indeks Produktivitas Relatif(IPR) } \\
& Usaha & 2005 & 2008 & 2010 \\
\hline 1 & Primer & 1,61 & 1,37 & 1,15 \\
2 & Sekunder & 0,49 & 0,56 & 0,66 \\
3 & Tertier & 0,81 & 0,96 & 0,99 \\
\hline
\end{tabular}

Berdasarkan hasil analisis diketahui IPR sektor primer (pertanian, pertambangan dan penggalinan) memiliki nilai diatas satu $(>1)$. Ini menunjukkan masih tingginya produktifitas relatif sektor primer dibandingkan sektor lainnya, walaupun kecenderungannya mengalami penurunan. Sementara itu sektor sekunder(industri pe-ngolahan, listrik dan kontruksi) dan sektor tertier(perdagangan, hotel \& restoran, angkutan dan komunikasi, keuangan dan jasa) produktifitasnya masih rendah, namun trennya mengalami peningkatan dari tahun 2005 hingga 2010. Ini menunjukkan terjadinya proses transformasi ekonomi di Kabupaten Garut.

\section{Potensi Ekonomi Garut Selatan Berbasis Sumberdaya Lokal}

Menurut Friedman dan allonso (1978), pengembangan wilayah dalam jangka panjang lebih ditekankan pada pengenalan potensi sumber daya alam dan potensi pengembangan lokal wilayah yang mampu mendukung pertumbuhan ekonomi, kesejahteraan so-sial, termasuk pengentasan kemiskinan dan ketertinggalan dalam rangka mencapai tujuan pembangunan. Berkaitan dengan hal tersebut, maka pengembangan wilayah lebih ditekankan pada penyusunan paket pengembangan wilayah terpadu dengan mengenali sektor strategis (potensial) yang perlu dikembangkan di suatu wilayah. Salah satu pendekatan dalam perencanaan pengembangan wilayah menurut Tarigan (2008) adalah pendekatan sektoral. Pendekatan sektoral dilakukan dengan mengelompokkan kegiatan pembangunan ke dalam sektor-sektor, selanjutnya masingmasing sektor dianalisis untuk menetapkan apa yang dapat dikembangkan (ditingkatkan) dari sektor tersebut guna mengembangkan wilayah.

Garut bagian selatan meliputi 16 kecamatan dan 125 desa yang terdiri dari Kecamatan Cisewu, Talegong, Caringin, Bungbulang, Mekarmukti, Pakenjeng, Pamulihan, Cikelet, Cisompet, Pameungpeuk, Cibalong, Cihurip, Peundeuy, Singajaya, Banjarwangi dan Cikajang, dengan luas wilayah mencapai $192.962 \mathrm{Ha}$ atau $63 \%$ dari luas Kabupaten Garut (Jenny, dkk, 2007). Jumlah penduduk Garut selatan tahun 2010 adalah 642.196 orang atau 26,74 persen dari seluruh penduduk Kabupaten Garut yaitu 2.401.248 orang (BPS, 2011)

Dilihat dari kondisi sumberdaya alam Garut Selatan memiliki potensi ekonomi yang besar untuk dikembangkan dalam sektor pertanian, perikanan, peternakan, pertambangan dan energi serta pariwisata.

Potensi Sektor Pertanian Perikanan dan Peternakan

Potensi Garut selatan sesuai dengan karakteristik wilayahnya masih didominasi oleh sekor pertanian (tanaman pangan, perkebunan, peternakan, perikanan dan 
kehutanan). Kontribusi sektor pertanian terhadap PDRB Garut selatan adalah 58,40\%. Sebagai leading sector, sektor pertanian menjadi prioritas dalampengembangan Garut Selatan. Saat ini pengembangan agribisnis komoditas unggulan muncul menjadi salah satu alternatif peluang investasi dalam pembangunan sektor pertanian. Beberapa komoditas dapat dikatagorikan sebagai komoditi unggulan dan prospektif (Tabel 2).

Tabel 2. Potensi Pertanian Komoditas Unggulan dan Prosfektif di Garut Selatan

\begin{tabular}{|c|c|c|c|c|}
\hline$\overline{\mathrm{No}}$ & Subsektor & Kelompok & Komoditas & Lokasi \\
\hline \multirow[t]{7}{*}{$\overline{1 .}$} & \multirow[t]{7}{*}{ Pertanian } & \multirow[t]{3}{*}{ Pangan } & Padi & $\begin{array}{l}\text { Pameungpeuk, Cibalong, Talegong, } \\
\text { Pakenjeng,Bungbu lang,Cikelet, } \\
\text { Cisewu, }\end{array}$ \\
\hline & & & Jagung & $\begin{array}{l}\text { Pamulihan, Peundeuy, Cikajang, } \\
\text { Cihurip, Pakenjeng }\end{array}$ \\
\hline & & & Kedelai & $\begin{array}{l}\text { Cibalong, Csompet, } \\
\text { Peundeuy, Cisewu }\end{array}$ \\
\hline & & \multirow[t]{4}{*}{ Hortikultura } & Cabe & $\begin{array}{l}\text { Cisewu, Talegong, Bungbulang, } \\
\text { Cihurip, Banjarwangi, Cikajang }\end{array}$ \\
\hline & & & Kentang & Cikajang, Pamulihan \\
\hline & & & Pisang & $\begin{array}{l}\text { Cisewu, Bungbulang, Mekarmukti, } \\
\text { Cikelet, Pameungpeuk, Cibalong, } \\
\text { Cisompet, Cihurip, Pamulihan }\end{array}$ \\
\hline & & & Jeruk & $\begin{array}{l}\text { Cikajang, Cisompet, Pakenjeng, } \\
\text { Cibalong, pameungpeuk, Cikelet }\end{array}$ \\
\hline \multirow[t]{7}{*}{2.} & \multirow{7}{*}{\multicolumn{2}{|c|}{ Perkebu-nan }} & Aren & $\begin{array}{l}\text { Cisewu, Caring in, Talegong, } \\
\text { Bunbulang, Pakenjeng, Cisompet, } \\
\text { Cikajang, Cihurip, Banjarwangi }\end{array}$ \\
\hline & & & Teh & $\begin{array}{l}\text { Pamulihan, Singajaya, Cikajang, } \\
\text { Cila-wu, Pakenjeng, } \\
\text { Banjarwangi,Pakenjeng }\end{array}$ \\
\hline & & & Kelapa & $\begin{array}{l}\text { Pamengpeuk, Cibalong, Cikelet, } \\
\text { Bungbulang, Caringin }\end{array}$ \\
\hline & & & Nilam & Talegong \\
\hline & & & Tembakau & $\begin{array}{l}\text { Pamulihan, Pekenjeng, Peundeuy, } \\
\text { Singajaya, Cikajang, Banjarwanagi }\end{array}$ \\
\hline & & & Karet & $\begin{array}{l}\text { Cibalong, } \\
\text { Pameungpeuk,Cisompet,Caringin, } \\
\text { Mek armukti, Bungbulang, } \\
\text { Pakenjeng }\end{array}$ \\
\hline & & & Kopi & $\begin{array}{l}\text { Bungbulang, Pamulihan, Cikajang, } \\
\text { Pakenjeng, Cỉhurip, Talegong }\end{array}$ \\
\hline \multirow[t]{3}{*}{3.} & \multirow[t]{3}{*}{ Perikanan } & \multirow[t]{3}{*}{ Laut } & $\begin{array}{l}\text { Udang,kera- } \\
\text { pu, lobster }\end{array}$ & Cibalong, Pameung peuk \\
\hline & & & Rumput laut & Cikelet, Pameungpeuk \\
\hline & & & Ikan hias & Cikelet \\
\hline \multirow[t]{4}{*}{4.} & \multirow[t]{4}{*}{ Peternakan } & \multirow[t]{4}{*}{$\begin{array}{l}\text { Ruminansia } \\
\text { besar }\end{array}$} & Sapi perah & $\begin{array}{l}\text { Cilawu, Cisurupan Cikajang, } \\
\text { Banjarwangi, }\end{array}$ \\
\hline & & & Sapi potong & $\begin{array}{l}\text { Pameungpeuk, Cikelet, Cibalong, } \\
\text { Cisompet, Bungbulang. }\end{array}$ \\
\hline & & & Domba & $\begin{array}{l}\text { Cikajang, Cilawu, Bungbulang, } \\
\text { Cibalong, Singajaya, Cisewu, }\end{array}$ \\
\hline & & & Kambing & $\begin{array}{l}\text { Bungbulang, Pameungpeuk, } \\
\text { Cikelet, Cibalong, Singajaya, }\end{array}$ \\
\hline
\end{tabular}

Sumber: Jenny (2007) dan Ade Bastiawan (2012) diolah

Pantai selatan Kabupaten Garut memiliki potensi perikanan yang cukup besar. Panjang pantai pesisir selatan Garut yang mencapai 72 kilometer yang berada di enam kecamatan yaitu Kecamatan Cibalong, Pameungpeuk, Cikelet, Pakenjeng, Bungbulang, dan Caringin, dan memiliki Zona Ekonomi Eksklusif (ZEE) 200 mil laut dengan luas areal penangkapan \pm 28.560 $\mathrm{km}^{2}$ (Hilda, 2010).

Potensi perikanan budidaya tambak adalah $1000 \mathrm{Ha}$ dan baru diman-faatkan sekitar 26,6 Ha (2,66\%). Saat ini budidaya tambak yang dikembangkan di Kabupaten Garut baru sebatas tambak udang. Padahal Potensi lainnya seperti tambak bandeng masih terbuka luas. Selain tambak, potensi area budidaya laut di Kabupaten Garut sekitar $3.400 \mathrm{Ha}$ dan baru dimanfaatkan sebesar $0,5 \mathrm{Ha}(0,01 \%)$ dan baru mengembangkan budidaya Kerapu. Padahal dengan ekosistem kelautan yang lengkap terdiri dari estuaria (24 ha), terumbu karang (525 ha), padang lamuna (75 ha), dan mangrove (50,9 ha), wilayah pesisir Kabupaten Garut sangat baik untuk areal budidaya seperti budidaya rumput laut, lobster, bandeng, ikan hias dan sebagainya. Kabupaten Garut Juga berpotensi sebagai areal budidaya kepiting bakau mengingat area perairan Estuaria dan Mangrove yang cukup besar.

Potensi perikanan tangkap diantaranya Tuna, Tongkol, Cakalang, Cumi-cumi, Layur, Kakap, Bawal Hitam, Kerapu, Baronang, Cucut Botol, Lobster dan ikan khias. Khusus untuk area penangkapan sampai zona teritorial (12 mil laut) diperkirakan pesisir selatan Garut memiliki potensi lestari (Maximum Sustainable Yield) sebesar 10.000 ton/tahun. Saat ini nelayan Kabupaten Garut baru memanfaatkan sekitar 49,94\% dari potensi yang ada. Hal ini membuka peluang bagi para investor di bidang perikanan tangkap untuk memanfaatkan potensi ter-sebut. Namun potensi alam yang berasal dari laut dan pantai di Perairan Pameungpeuk belum dapat diolah sepenuhnya, diperkirakan baru $15 \%$ karena belum didukung oleh berbagai sarana. Dalam perkembangan Tempat Pelelangan Ikan (TPI) di Kabupaten Garut Cilauteureun merupakan sentra dari keempat Tempat Pendaratan Ikan (TPI) yang tersebar di pantai selatan Garut dengan jumlah armada penangkapan motor (KM) 15 unit, motor tempel 168 unit dan perahu tanpa motor 13 unit. Selain TPI Cilauteueureun terdapat pula TPI Cimari, Rancabuaya dan Sancang (Hilda, 2010).

\section{Potensi Pertambangan Bahan Galian dan Energi}

Bahan tambang potensial untuk dikembangkan di Kabupaten Garut adalah 
bahan galian golongan $\mathrm{C}$ dan bahan lain seperti perlit, obsidian, batu setengah permata, kaolin, batu templek, pasir, sirtu, tras, tanah urug, lempung, batu apung, belerang, toseki, dan batu silika. Kontribusi barang tambang dalam perekonomian Kabupaten Garut kurang lebih sebesar 0,20\% (Pemkab. Garut, 2010).

Tabel 3. Potensi Sumberdaya Mineral Batubara dan Energi di Garut Selatan

\begin{tabular}{|c|c|c|c|}
\hline No & $\begin{array}{l}\text { Jenis Sumber Daya } \\
\text { Mineral dan Energi }\end{array}$ & Lokasi (Kecamatan) & Daerah Prospek \\
\hline$\overline{1}$ & Emas dmp & $\begin{array}{l}\text { Pamulihan, Pakenjeng, } \\
\text { Talegong, Cisewu, } \\
\text { Caringin, Banjarwangi, } \\
\text { Cikajang, Peundeuy, } \\
\text { Singajaya, Cibalong, } \\
\text { Cisompet, Bungbulang, } \\
\text { Mekarmukti }\end{array}$ & $\begin{array}{l}\text { Ciarinem, Cijahe, Sukul, } \\
\text { Cijaringao, Pasirlangu }\end{array}$ \\
\hline 2 & Pasir besi & $\begin{array}{l}\text { Cibalong, Pameungpeuk, } \\
\text { Cikelet, Pakenjeng, } \\
\text { Caringin, Mekarmukti }\end{array}$ & $\begin{array}{l}\text { Cimerak,Cibera,Cijayana,S } \\
\text { ayangheulang,Citang- } \\
\text { geuleuk, Rancabuaya }\end{array}$ \\
\hline 3 & Bijih besi & $\begin{array}{l}\text { Cibalong, Cikelet, } \\
\text { Bungbulang, Caringin, }\end{array}$ & $\begin{array}{l}\text { Banyuasih, Ciawitali, } \\
\text { Cileuleuy, Cikabunan }\end{array}$ \\
\hline 4 & Belerang & Cisurupan, Wanaraja & Papandayan, Talagabodas \\
\hline 5 & Batubara & Singajaya, Cibalong & Girimukti, Dahu \\
\hline 6 & Batu Templek & Cisewu, Caringin & Loa, Sukarame \\
\hline 7 & Kaolin & Malangbong & Karaha, Citeras \\
\hline 8 & Obsidian & Pasirwangi & Gn. Kiamis \\
\hline 9 & Batu Andesit & $\begin{array}{l}\text { Cisewu, Cikajang, } \\
\text { pakenjeng }\end{array}$ & \\
\hline 10 & Batu gamping & Caringin, Cisewu & Cikabunan \\
\hline 11 & Batu setengah Permata & $\begin{array}{l}\text { Caringin,Cisewu,Bungbula } \\
\text { ng,Cisompet,Pakenjeng, } \\
\text { Pameungpeuk }\end{array}$ & $\begin{array}{l}\text { G.Kencana,Sirnajaya, } \\
\text { Cilubang, Cipicung, }\end{array}$ \\
\hline 12 & Granit & Bungbulang & Gunamekar \\
\hline 13 & Mangan & Cibalong, Cisompet & Cicuri, Jatisari \\
\hline 14 & Tembaga & Bungbulang, Caringin & \\
\hline 15 & Energi panas bumi & $\begin{array}{l}\text { Darajat, Kamojang } \\
\text { (Pasirwangi) }\end{array}$ & $\begin{array}{l}\text { Cilayu, Ciarinem, Gn } \\
\text { Papandayan Gn. Talagabo- } \\
\text { das, G. Guntur Masigit, }\end{array}$ \\
\hline 16 & Energisumber daya air & $\begin{array}{l}\text { Pamulihan,Bungbulang, } \\
\text { Cibalong }\end{array}$ & $\begin{array}{l}\text { Cibatarua,Cimerak, } \\
\text { Cirompang }\end{array}$ \\
\hline
\end{tabular}

Sumber : RPJPD, Garut 2010

\section{Potensi Pariwisata}

Kabupaten Garut merupakan salah satu wilayah yang memiliki potensi pengembangan industri pariwisata cukup besar. Daerah tujuan wisata terdiri dari 30 wisata alam lima wisata budaya dan tiga wisata rekreasi yang sebagian besar tersebar di wilayah pengembangan Garut Tengah dan Garut Selatan.

Beberapa kecamatan di Garut Selatan memiliki pantai yang indah dan potensial untuk dikembangkan menjadi tujuan wisata dengan aktifitas berperahu, memancing, bermain pasir dan air laut, berziarah ke makam keramat, menikmati keindahan teras merin dan karang laut, melihat aktivitas nelayan, melihat proses pengolahan ikan, serta melihat kegiatan pasar lelang ikan. Daerah potensial untuk wisata pantai adalah Kecamatan Caringin, Bungbulang, Mekarmukti, Pakenjeng, Cikelet, Pameungpeuk dan Cibalong. Sedikitnya ada 10 kawasan wisata dengan pantai indah-nya seperti Santolo, Karangparanje, Sayangheulang, Pantai Cibalong, Gunung Geder, Cijeruk Indah, Manalusu, Cicalobak, Puncak Guha dan Rancabuaya. Pariwisata budaya juga bisa dilakukan di Kampung Adat Dukuh yang berlokasi diKecamatan Cikelet.

\section{Analisa Lingkungan Internal Daerah Tertinggal di Garut Selatan}

Menurut Friedman dan Allonso (1978) pengembangan wilayah pada hakekatnya merupakan suatu usaha bagaimana memanfaaatkan dan mengkombinasikan faktor internal (kekuatan dan kelemahan) dengan faktor eksternal (peluang dan ancaman) yang ada sebagai suatu potensi yang dapat dimanfaatkan untuk meningkatkan produksi suatu wilayah.

Permasalahan pengembangan daerah tertinggal di Garut Selatan dipengaruhi oleh faktor eksternal dan internal wilayah tersebut. Lingkungan internal berupa kekuatan (Strenghth) wilayah tertinggal di Garut Selatan meliputi: luasnya lahan pertanian sebesar $52 \%$ dari total wilayah Garut yang berupa wilayah pertanian intensif dengan ketinggian 0-25 m dpl, komitmen politik Pemerintah Kabupaten Garut dalam pengembangan Wilayah tertinggal di Garut Selatan, Sumberdaya dengan Sektor Unggulan yang dimilikinya serta ditetapkannya Kecamatan Pameungpeuk dan Bungbulang sebagai pusat pertumbuhan Garut Selatan dengan aktifitas pengembangan pariwisata dan konservarsi (RJPMD Garut, 2010).

Berdasarkan penelitian Gumilar (2009), prioritas pengembangan sektor unggulan untuk wilayah Garut Selatan terdiri dari : (1) sektor pertanian di. Caringin, Talegong, Mekarmukti, Pamulihan, Cibalong, Peundey dan banjarwangi (2) sektor industrti pe- 
ngolahan di Bungbulang,Cikelet, (3) sektor perdagangan di Cikajang, Pameungpeuk dan Cisewu, (4) Listrik dan gas di Pakenjeng, Cisewu dan Singajaya, banjarwangi dan Cihurip, (5) sektor angkutan di Cihurip Pamulihan, Cibalong, dan Cisewu, (6) sektor pertambangan di Cisewu, Caringin, $\mathrm{Pa}-$ kenjeng dan Singajaya, (7) Sektor Jasa di Cikajang, (8) sektor konstruksi di Cikelet, serta (9) sektor keuangan di Cikajang, Pameungpeuk dan Bungbulang.

Kota Pameungpeuk sebagai salah satu pusat pertumbuhan baru untuk melayani perkembangan aktivitas di Garut Selatan, Tasikmalaya Selatan, dan Ciamis Selatan. Kondisi aksesibilitas eksisting yang menghubungkan Pameungpeuk, Cikajang, dan Garut retatif memadai dibandingkan dengan poros utara-selatan lainnya. Se-lanjutnya ditetapkan Cikajang sebagai sentra komoditas holtikultura di Garut Selatan agar Cikajang juga berperan men-jadi sentra produksi agribisnis hortikultura di Kabupaten Garut melalui peningkatan kuantitas dan kualitas fasilitas dan aksesibitas.

Kelemahan (Weakness) yang membatasi dalam pengembangan wilayah tertinggal di Garut selatan diantaranya :

(1). Terbatasnya kondisi infrastruktur terutama infratruktur dasar, seperti sarana jalan, jaringan telepon, jaringan listrik, dan sarana pelayanan publik lainnya terkait akses pelayanan pendidikan dan kesehatan. Selama ini akses terhadap infrastruktur tersebut masih belum terpenuhi dengan baik.

(2).Karateristik geomorfologis memiliki kemiringan lereng lebih dari 15 persen, lebih dari 80 persen luas wilayahnya merupakan kawasan konservasi (non budidaya) dan rawan bencana sehingga kurang menunjang kawasan terbangun dan kurang memancing investor untuk berinvestasi

(3).Rendahnya kemampuan sosial dan ekonomi masyarakat di wilayah Garut Selatan. Pada tahun 2010 penduduk Garut selatan yang tergolong miskin berjumlah 24,74 persen. Dari penduduk Kabupaten Garut sekitar 2,3 juta orang, lebih dari 6000 orang yang buta aksara berada di wilayah Garut Selatan.
(4).Belum Optimalnya fungsi pusat pelayanan di Wilayah Garut Selatan.

Ketersediaan fasilitas pendidikan dasar sembilan tahun di Garut Selatan sudah bisa memenuhi kebutuhan, Namun untuk fasilitas pendidikan tingkat lanjutan umum di beberapa wilayah masih belum tersedia seperti di Kecamatan Mekarmukti, Pamulihan, Cibalong dan Cihurip. Untuk fasilitas kesehatan perlu segera dibangun rumah sakit dan puskesmas yang ada dilengkapi fasilitas rawat inap guna me-mudahkan pelayanan kesehatan pada masyarakat. Balai pengobatan sangat kurang tersedia di Garut Selatan, sehingga perlu segera dibangun agar peningkatan kualitas kesehatan masyarakat bisa terpenuhi (Gumilar, 2010).

Keberadaan sarana perhubungan merupakan pendukung perkembangan ekonomi wilayah guna memudahkan mobilitas dan interaksi penduduk. Sarana perhubungan berupa terminal mengindikasikan keberadaan rute angkutan yang rutin melewati daerah tersebut. Hanya empat kecamatan di Garut selatan yang memiliki terminal yaitu Kecamatan Pameungperuk, Cikajang, Bungbulang dan Singajaya. Terminal di Singajaya yang melayani wilayah timur laut, wilayah barat dilayani oleh terminal di Kecamatan Bungbulang, dan untuk di tenggara dilayani terminal di Pameungpeuk. Kegiatan perdagangan di Garut selatan hanya ditopang oleh dua buah pasar induk dan sisanya berupa pasar harian di hampir setiap kecamatan dan dua unit STA (Sub Terminal Agribisnis) yang berada di Kecamatan Cikajang dan Kecamatan. Mekarmukti (Ristania, 2007).

Keterbatasan prasarana dan sarana komunikasi, transportasi, kesehatan, pendidikan dan pelayanan lainnya menyebabkan masyarakat di daerah tertinggal mengalami kesulitan untuk melakukan aktivitas ekonomi dan sosial sehingga akan menurunkan kemampuan sosial dan ekonomi masyarakatnya.

\section{Analisa Lingkungan Eksternal Daerah Tertinggal di Garut Selatan}

Beberapa peluang (opportunities) yang dapat mendukung bagi pengembangan wilayah tertinggal di Garut selatan antara 
lain: (1) menurut RTRW Provinsi Jawa Barat Kabupaten Garut diarahkan menjadi kawasan andalan dengan prioritas unggulan sektor pertanian dan industri pengolahan pertanian, perikanan dan industri pengolahan perikanan, wisata alam dan minat khusus, serta kegiatan pertambangan mineral logam dan non logam, (2) adanya pengembangan jalur lintas selatan sehingga akan meningkatkan aksesibilitas masyarakat, (3) terbukanya kesempatan bermitra dengan pihak swasta (Bappeda Garut, 2010).

Faktor eksternal yang menjadi ancaman (threath) sehingga Garut bagian selatan mengalami kesulitan dalam percepatan pembangunannya antara lain:

1.Wilayah selatan Jawa merupakan darah tertinggal yang didiami sepertiga penduduk Pulau Jawa dan sebagian besar hidup di bawah garis kemiskinan (wahid, 2006).

2. RTRW Provinsi Jawa Barat berdasarkan Perda No.22/2010, menetapkan 253.129 Ha $(81,39 \%)$ wilayah Kabupaten Garut sebagai kawasan lindung dan Kawasan budidaya sisanya $18,61 \%$. Konsekuensinya perlukehati-hatiandalam pemanfaatan sumberdaya alam termasuk pemanfaatan lahan untuk pembangunan infrastruktur dan alih fungsi lahan yang tidak sesuai dengan arahan pemanfaatan tata ruang. Kawasaan lindung tersebut sebagian besar berada di wilayah Garut Selatan yang mana memiliki potensi pertambangan cukup besar, namun dapat mengancam kelestarian alam dan lingkungan.

3. Keterbatasan Anggaran Pembangunan Guna mempercepat pembangunan daerah tertinggal dibutuhkan dana yang luar biasa besar. Dana ini dapat bersumber dari Anggaran Pendapatan dan Belanja Negara (APBN), Anggaran Pendapatan dan Belanja Daerah (APBD), Dana Alokasi Khusus (DAK), dan Dana Swasta dan Masyarakat. Namun, pembiayaan yang diberikan pemerintah (konvensional) tidak selamanya dapat mengatasi kebutuhan dana karena adanya keterbatasan dana yang dimiliki pemerintah pusat sehingga tidak dapat menjawab semua P3D yang di berikan desa tertinggal maka diperlukan strategi pembiayaan lainnya.
Tabel 5. Penetapan Kawasan Lindung di Garut Selatan Sampai Tahun 2011

\begin{tabular}{|c|c|c|}
\hline No & $\begin{array}{c}\text { Jenis Kawasan } \\
\text { Lindung }\end{array}$ & Wilayah \\
\hline \multirow[t]{2}{*}{1} & $\begin{array}{l}\text { Kawasan yang } \\
\text { memberikan } \\
\text { perlindungan }\end{array}$ & $\begin{array}{l}\text { Cikajang, } \\
\text { Banjarwangi, } \\
\text { Bungbulang, }\end{array}$ \\
\hline & kawasan bawahnya & $\begin{array}{l}\text { Cisewu, } \\
\text { Caringin,Cisompet, } \\
\text { Pameungpeuk, } \\
\text { Cikelet }\end{array}$ \\
\hline 2. & $\begin{array}{l}\text { Kawasan Hutan } \\
\text { Produksi yang } \\
\text { berfungsi lindung }\end{array}$ & $\begin{array}{l}\text { Cikajang, } \\
\text { Banjarwangi, } \\
\text { Bunbulang, Cikelet, } \\
\text { Caringin, Cisewu, } \\
\text { Cisompet, } \\
\text { pameungpeuk } \\
\text { Cihurip }\end{array}$ \\
\hline 3. & $\begin{array}{l}\text { Kawasan } \\
\text { perlindungan } \\
\text { setempat (sem- } \\
\text { padan pantai, } \\
\text { sungai,danau) }\end{array}$ & $\begin{array}{l}\text { Tersebar di } \\
\text { kabupaten Garut } \\
\text { dan sepanjang } \\
\text { pantai selatan } \\
\text { Kabupaten Garut }\end{array}$ \\
\hline \multirow[t]{4}{*}{4.} & $\begin{array}{l}\text { Kawasan Suaka } \\
\text { alam dan cagar alam }\end{array}$ & \\
\hline & $\begin{array}{l}\text { Pantai berhutan } \\
\text { bakau }\end{array}$ & $\begin{array}{l}\text { Cibalong, } \\
\text { Pameungpeuk dan } \\
\text { Caringin }\end{array}$ \\
\hline & $\begin{array}{l}\text { Pantai beterumbu } \\
\text { karang }\end{array}$ & $\begin{array}{l}\text { Caringin, } \\
\text { Bungbulang dan } \\
\text { Mekarmukti }\end{array}$ \\
\hline & $\begin{array}{l}\text { Taman nasional } \\
\text { tanam hutan raya } \\
\text { dan Taman wisata } \\
\text { alam }\end{array}$ & $\begin{array}{l}\text { Cagar alam } \\
\text { sancang. Cijayana } \\
\text { dan Bungbulang }\end{array}$ \\
\hline 5. & $\begin{array}{l}\text { Kawasan rawan } \\
\text { bencana }\end{array}$ & $\begin{array}{l}\text { Talegong, Cisewu, } \\
\text { Pamulihan, } \\
\text { Cikajang dan } \\
\text { Banjarwangi }\end{array}$ \\
\hline
\end{tabular}

Sumber : RPJPD Garut, 2010

\section{Strategi Pembangunan Daerah Tertinggal di Kabupaten Garut Strategi S-O}

Strategi S-O merupakan strategi yang menggunakan kekuatan internal untuk memanfaatkan peluang eksternal guna memperoleh keuntungan bagi pembangunan daerah tertinggal. Beberapa alternatif strategi S-O yang dihasilkan sebagai berikut :

1. Meningkatkan akses kerjasama antara pemerintah propinsi dengan kabupaten yang dituangkan dalam kebijakan pembangunan. Berdasarkan kekuatan yang dimiliki oleh Kabupaten Garut.

2. Mendorong kesempatan berusaha dan lapangan kerja berbasis sumberdaya lokal dengan memanfaatkan sektor pertanian, pertambangan dan pariwisata sebagai leading sector melalui produk unggulan daerah dan membuka peluang kemitraan dan kerjasama dengan pihak swasta. 
Garut selatan memiliki keunggulan komparatif di sektor pertanian, namun masih rendahnya industri yang memanfaatkan hasil-hasil pertanian, sehingga perdagangan antar wilayah yang dilakukan lebih dominan berupa bahanbahan mentah hasil pertanian. Untuk itu perlu dikembangkan agroindustri yang dapat memperpanjang rantai agribisnis, memberikan nilai tambah yang lebih besar.

3. Optimalisasi fungsi pusat pelayanan di wilayah Garut Selatan. Guna pengembangan Wilayah Garut Selatan sebagai pusat agrobisnis di Kabupaten Garut, maka pusat pelayanan yang ada harus berfungsi optimal. Wilayah Garut Selatan telah memiliki tiga kecamatan potensial yang telah berfungsi sebagai pusat pelayanan. Dengan meningkatkan pelayanan di tiga kecamatan(Cikajang, Pameungpeuk dan Bungbulang), maka akan dicapai cakupan pelayanan bagi Wilayah Garut Selatan dan sekitarnya. Pelayanan yang perlu menjadi prioritas adalahpemenuhan kebutuhan sarana kesehatan dan sarana perekonomian, yang terkait dengan pemenuhan kebutuhan dasar.

\section{Strategi W-O}

Strategi W-O merupakan strategi yang digunakan untuk mengatasi kelemahan yang dimiliki dalam memanfaatkan peluang yang ada. Beberapa alternatif strategi W-O yang dihasilkan sebagai berikut :

1.Pembangunan sarana dan prasarana untuk meningkatkan pembangunan di wilayahwilayah tertinggal dan terpencil agar dapat tumbuh dan berkembang lebih cepat dengan melibatkan Kementerian Negara Pembangunan Daerah Tertinggal dan Pemda. Strategi ini untuk mengatasi kelemahan Kabupaten Garut berupa kondisi geografis yang tidak rata dan labil. Peningkatan kualitas jaringan jalan. Jaringan jalan merupakan elemen utama yang mendorong perkembangan suatu wilayah. Jaringan jalan yang ada masih kurang memadai untuk mendukung pergerakan masyarakat dan untuk distribusi hasil-hasil pertanian di Wilayah
Garut Selatan. Selain itu jaringan jalan yang baik dapat mendukung tumbuh kembangnya objek-objek wisata di Wilayah Garut Selatan sehingga dapat lebih mudah berkembang. Pengembangan jalan poros desa merupakan salah satu strategi dalam pengembangan infrastruktur di wilayahGarut bagian selatan.

2. Strategi peningkatan kualitas sumberdaya manusia, dengan lebih melibatkan Peran aktif dari Institusi Pendidikan, Balai penelitian dan Diklatda, LPK serta partisipasi aktif masyarakat dan seluruh stakeholder. Selain itu pembinaan kapasitas kelembagaan seperti pembinaan dan pemberdayaan kelompok petani/ peternak dan nelayanmengenai peningkatan nilai tambah produk

3.Meningkatkan kualitas pendidikan di wilayah Garut bagian selatan iharapkan akan mampu meningkatkan kesejahteraan masyarakat secara tidak langsung. Sementara itu, agar sektor pertanian dan pariwisata maju, juga perlu ditingkatkan fasilitas pendidika dengan keahlian khusus, seperti sekolah menengah kejuruan dan sekolah tinggi yang bergerak di sektor pendidikan pertanian, perikanan dan pariwisata. Elemen-elemen yang perlu menjadi perhatian dalam sasaran itu mencakup peningkatan jumnlah fasilitaspendidikan formal, peningkatan kualitas pengajar dan tenaga ahli, serta kualitas pendidikannya.

\section{Strategi S-T}

Strategi S-T merupakan strategi yang menggunakan kekuatan internal untuk menghindari atau mengurangi dampak ancaman eksternal. Beberapa alternatif yang dihasilkan antara lain :

1. Membuka keterisolasian daerah Garut Selatan dengan sumberdaya alam yang potensial untuk dikembangkan sebagai sektor unggulan melalui integrasi dengan pengembangan pusat-pusat pertumbuhan ekonomi.

2. Pengembangan ekonomi berdasarkan potensisumberdayalokal.Pengembangaan ekonomi lokal mendasari konsepnya pada 
pengembangan kewirausahaan lokal serta tumbuh kembangnya perusahaanperusahaan lokal, kerja sama pemerintah lokal dengan swasta dan lembaga-lembaga lainnya dalam mengelola sumber-sumber yang potensial untuk mendorong aktivitas ekonomi. Konsep pengembangan ekonomi lokal mengembangkan dan meningkatkan peran elemen-elemen endogenous development dalam kehidupan sosial ekonomi lokal dan melihat keterkaitan serta integrasinya secara fungsional dan spasial dengan wilayah yang lebih luas (Ma'rif : 2000)

\section{Strategi W-T}

Strategi W-T merupakan strategi yang mengurangi kelemahan internal dan menghindari ancaman eksternal yang ada. Beberapa alternatif strategi W-T yang dihasilkan antara lain :

1. Pengelolaan fungsi kawasan lindung. Untuk menjaga kelestarian lingkungan maka terpeliharanya fungsi kawasan lin-

Tabel 6. Matrik SWOT Strategi Pengembangan Garut Selatan

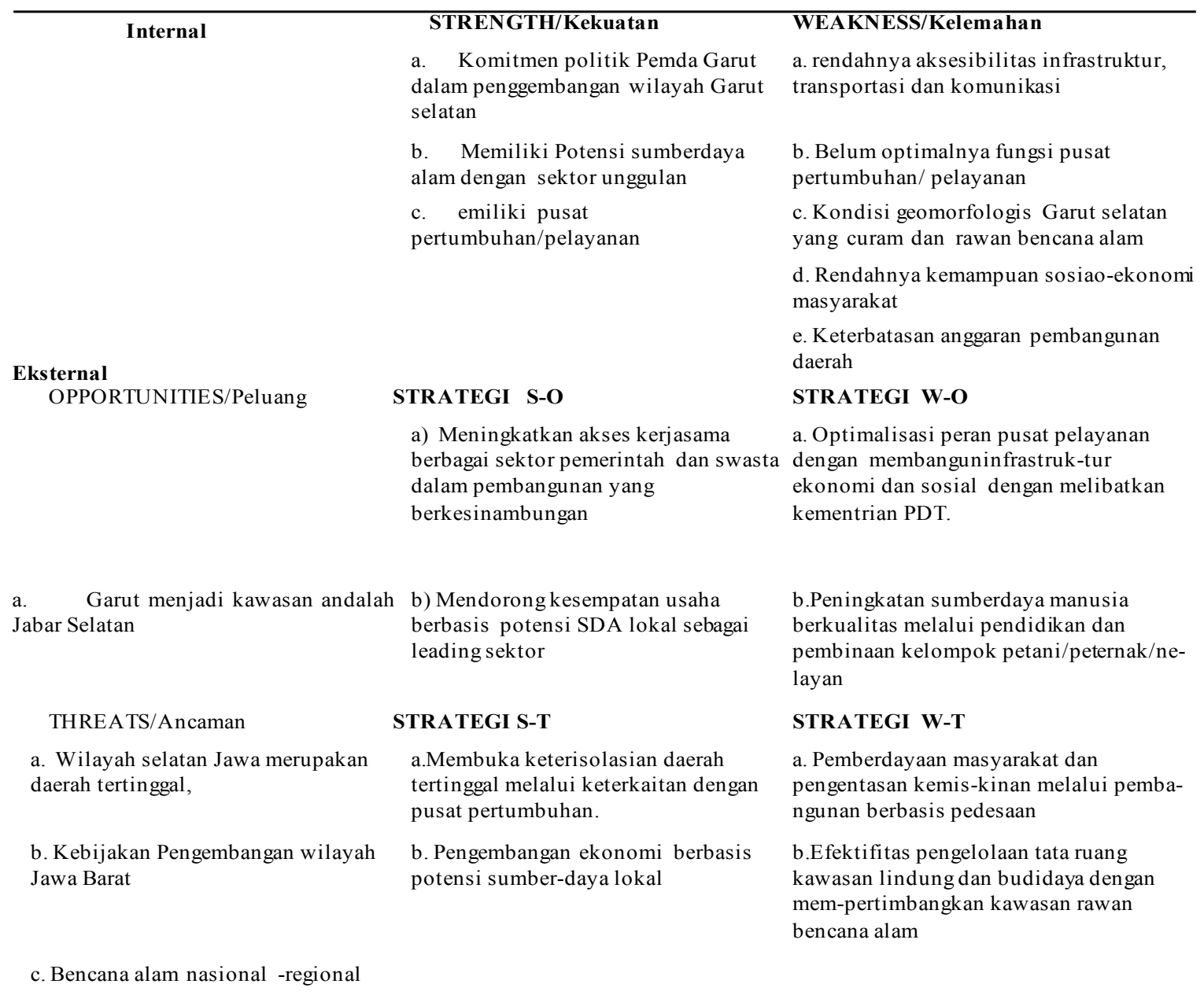

dung merupakan hal yang mutlak harus dilakukan. Dalam rangka mencapai tujuan sebagai pusat agribisnis dan pariwisata, maka wilayah Garut bagian selatan sebagai wilayah rawan bencana harus memperhatikan fungsi wilayah konservasi untuk menekan kemungkinan terjadinya bencana seminimal mungkin .

2. Karena keterbatasan lahan terkait kondisi geografis untuk budidaya, pengembangan sektor pertanian di Wilayah Garut
Selatan perlu dilakukan inovasi spesifik agar fungsi perlindungan (konservasi) dan peningkatan produktivitas lahan bisa berjalan searah. Salah satu pilihan adalah mengembangkan sistem agroforestry dan atau pertanian terpadu. 


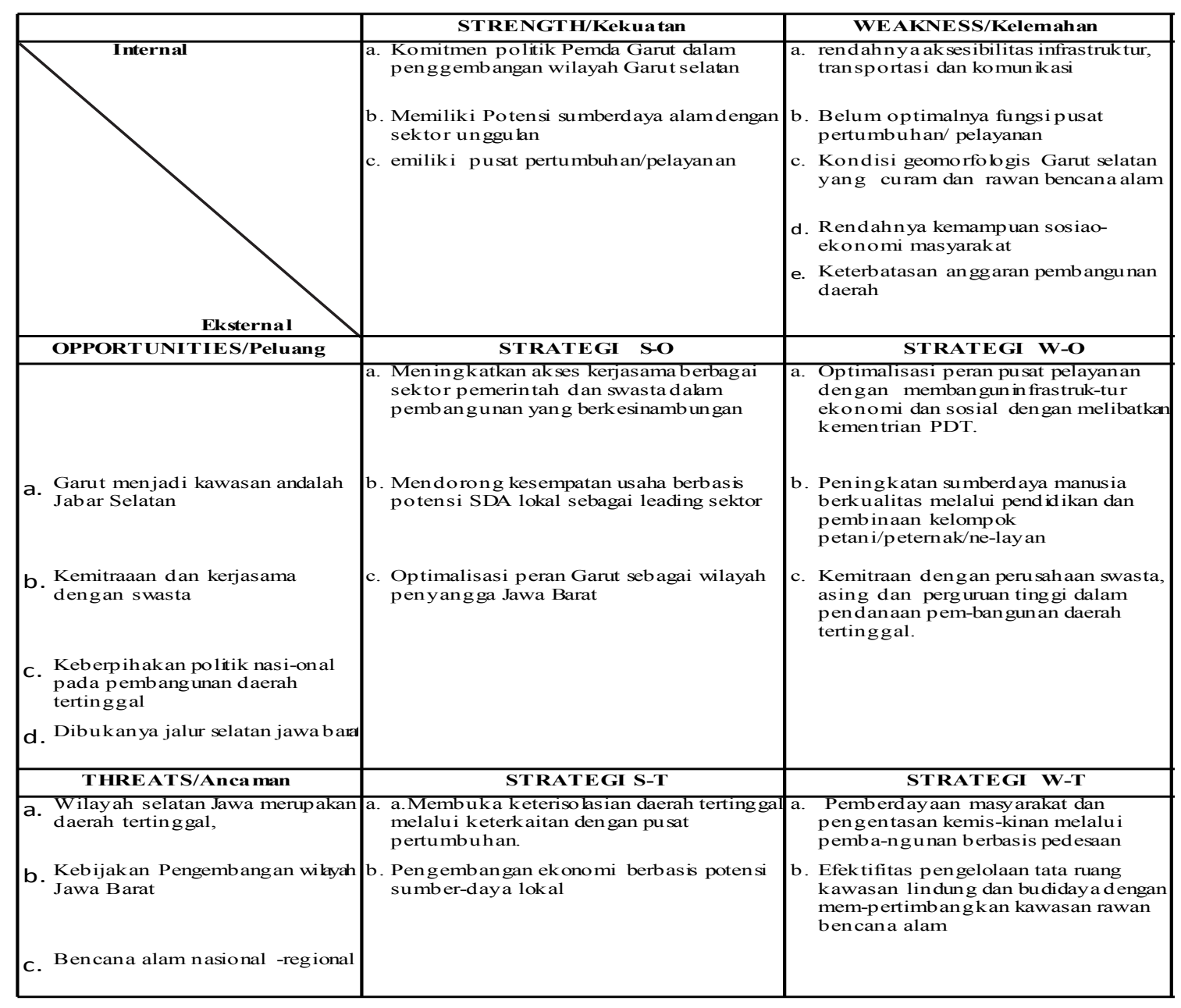

Gambar 1. Matrik SWOT Strategi Pengembangan Garut Selatan

\section{SIMPULAN}

Kabupaten Garut memiliki sumberdaya alam yang berciri sektor pertanian dan agroindustri. Indeks produktifitas relatif sek-tor primer (pertanian dan pertambangan) lebih tinggi dibandingkan sektor lainnya namun kecenderungannya mengalami pe-nurunan. Terjadinya proses transformasi ekonomi di Kabupaten Garut dari sektor primer ke sektor sekunder dan tersier. Kondisi sumberdaya alam Garut Selatan memiliki potensi ekonomi yang besar untuk dikembangkan dalam sektor pertanian, peternakan, peikanan, pertambangan dan energi serta pariwisata

Strategi pengembangan daerah tertinggal di wilayah Garut selatan adalah memadukan pembangunan sektoral dan kewilayahan yang berbasis potensi lokal dengan cara meningkatkan akses kerjasama pemerintah dan swasta dalam pembangunan yang berkelanjutan. Mendorong kesempatan usaha berbasis potensi sumberdaya alam sebagai leading sektor yaitu pertanian, peternakan, perikanan dan pariwisata dengan mengembangkan komoditas unggulan spesifik lokasi dan produk olahan melalui teknologi tepat guna dan perluasan pemasaran. Optimalisasi peran pusat pertumbuhan dengan cara melengkapi ketersediaan infrastruktur dan memperkuat keterkaitan sosial ekonomi dengan daerah pelayananya, Optimalisasi peran Kabupaten Garut sebagai wilayah penyangga Jawa Barat dengan penataan kawasan lindung dan budidaya secara integratif, serta peningkatan kualitas dan pemberdayaan masyarakat melalui pendidikan/keterampilan dan pembinaan kelembagaan berbasis pedesaan.

Perlu dibangun sistem informasi Garut Selatan yang memuat potensi sumberdaya alam, potensi bencana, rencana program dan pelaksananya sebagai bahan informasi bagi pihak terkait. Berhubung sebagian besar wilayah Garut selatan ditetapkan sebagai kawasan lindung dan konservasi alam, maka 
dapat dikembangkan kegiatan agroforestry, agroindustri dan sektor pariwisata, sedangkan eksploitasi sektor pertambangan apabila akan dikembangkan harus disertai industri pengolahan hasil tambang di lokasi setempat sehinnga meningkatkan nilai tambah..

\section{DAFTAR PUSTAKA}

Amilda Ristania, 2007. Thesis, Identifikasi Keterkaitan Pusat pertumbuhan di Kabupaten Garut Bagian Selatan Sebagai Wilayah Tertinggal http:// digilib.itb.ac.id/gdl.php?mod=bro wse \& op $=$ read\&id=jbptitbp - gdlamildarist-27248. 2012-06-19

Badan Pusat Statistik, 2011. Kabupaten Garut dalam Angka 2011, BPS, Pemda Kabupaten Garut

Bapeda, 2010. Kajian Pengembangan Kawasan Andalan Kabupaten Garut, Pemda Kabupaten Garut.

Bastiawan, ade. 2012. Komoditas Unggulan Garut. http://bastiawanade. Blogspot. .com /2012/07/komoditas-unggulangarut.html

Budiharsono, Sugeng, 2001, Teknis Analisis Pembangunan Wilayah Pesisir dan Lautan, Pradnya Paramitha, Jakarta.

Djuwendah, Endah, dkk, 2009. Pengarahan Pusat Pertumbuhan Melalui Analisis Keunggulan Komparatif di Kabupaten Garut, Agrikultura Vol 20 No 3 Faperta unpad

Friedman, John and Allonso, 1978. Regional Economic Development and Planning, Mass, MIT Press
Gumilar, Firman, 2009. Kajian disparitas pembangunan antar wilayah sebagai arahan pengembangan wilayah berbasis potensi lokal di kabupaten garut, Sekolah Pasca sarjana, IPB.

Jenny Ratna Suminar, dkk, 2007. Studi Evaluasi Kebijakan Pengembangan Kabupaten Garut Bagian Selatan, lemlit Unpad, Bandung. http://www.endaesyudha.com/ elibrary/upload/\%286.328\%29\%20 studi_evaluasi_kebijakan pengembangan.pdf

Lestari, Hilda, dkk, 2010. Penyusunan data Spasial Sumberdaya Alam dan Kebencanaan sebagai Acuan RTRW dan Pengembangan di Garut Selatan, LIPI

Ma'rif, Samsul, 2002. Ekonomi Wilayah dan Kota, Ekonomika dalam Perencanaan Identifikasi Sektor Strategis, Diktat Kuliah PWK UNDIP Semarang, 2002

Pemda Garut, 2010. Lampiran Peraturan Daerah Kabupaten Garut Nomor 4 Tahun 2010 tentang Rencana Pembangunan Jangka Panjang Daerah

Pemda Garut, 2010. RPJPD Kabupaten garut 2005-2025. http://www. garutkab.go.id/galleries/pdf link/pemerintahan/kebijakan/ RPJPD_2005-2025.pdf.diakses Mei 2013.

Tarigan R. 2008. Perencanaan Pembangunan Wilayah. Jakarta. PT Bumi Aksara.

Wahid, Abdul. 2006. Strategi Pembangunan Daerah Tertinggal, Skripsi Prodi Ekonomi Pertanian dan Sumberdaya, IPB, Bogor 